\title{
EFFICIENCY ANALYSIS OF TRADITIONAL TEA FARMS IN IRAN
}

\author{
Z. Ghaderi ${ }^{1}$, M. H. Menhaj ${ }^{2}$, M. Kavoosi-Kalashami ${ }^{3}$, S. M. Sanjari ${ }^{4}$ \\ *Corresponding author E-mail: mmenhaj@guilan.ac.ir
}

A R T I C L E I N F O
Original Article
Received: 25 May 2019
Accepted: 08 June 2019
doi:10.5937/ekoPolj1902423G
UDC 519.86:[631.1.017.3+663.9(55)

Keywords:

Production efficiency, data envelopment analysis, tea production, Guilan Province

JEL: Q12, C61, D22

\begin{abstract}
A B S T R A C T
This study aimed at analyzing technical, allocative and economic efficiency of tea farms in Fouman County of Guilan Province, Northern Iran. Data were collected through questionnaire and face-to-face interviews with 200 tea farmers in 2017. The data then were analyzed using descriptive statistics, data envelopment analysis (DEA), as well as correlation analysis. The average technical, allocative and economic efficiency, assuming constant return to scale in input-oriented model, were found to be 86,71 and 61 percent respectively. These figures for variable return to scale were 87,74 and 65 percent respectively. These results indicate that over 60 percent of the surveyed farms enjoyed scale efficiency. Of those socio characteristics affecting tea farmer's efficiency: age, educational level and family size had positive and significant correlation with technical efficiency. The findings suggest that, the elderly and better educated farmers combined their previous knowledge of farming adopting proper farming practices may achieve production efficiency.
\end{abstract}

(C) 2019 EA. All rights reserved.

\section{Introduction}

Tea (Camellia Sanseis) is one of the most important agricultural crops and the second most popular beverage after water across the world. Black tea was introduced into Europe in the early 16th century and gradually was popularized among all classes of people in the second half of the 19th century as a public soft drink (Moezi, 2009). In Iran, interests to grow tea were triggered because of the economic significance of

1 Z. Ghaderi, MSc of Rural Development, Department of Agriculutral Economics, University of Guilan, Iran, Phone: +989187890922, email: Zghaderi@gmail.com

2 M. H. Menhaj, Ph.D., Assistant Professor, Department of Agricultural Economics, University of Guilan, Iran, Phone: +989111377057, email: mmenhaj@guilan.ac.ir ORCID ID (https://orcid.org/ 0000-0001-8065-1361)

3 M. Kavoosi-Kalashami, Ph.D., Assistant Professor, Department of Agricultural Economics, University of Guilan, Iran, Phone: +989113317045, email: mkavoosi@guilan.ac.ir

4 S. M. Sanjari, MSc of Rural Development, Expert in charge, Iran Tea Organization, Lahijan, Iran, Phone: +989112446625, email: msanjari@gmail.com 
this product in trade and its considerable share in imports. After several disperse and unsuccessful attempts, the first tea farm Iran was eventually founded in Lahijan County in 1900 (Iran Tea Company Publication, 1958). Since only central North of Iran has the suitable natural conditions and temperate climate, tea farming was developed extensively in these regions so that its acreage was increased from 1,000 hectare in 1933 to 30,000 hectares in 1973 (Iran Tea Company Publication, 1972). According to the World Food Organization (2017), Iran is the ninth largest tea producer in the world.

Since the late 1990 when the governmental monopoly started to abolish and tea production and marketing were assigned to the private sector, some tea farms have been withdrawn from the production cycle (Ghasemi, 2008). According to the agricultural census of the Statistical Center of Iran, the acreage of tea farms was 1,862 ha with 37,000 tea farmers in 2016 (Iran Statistical Center: Survey of Agriculture, 2016). According to data on green leaf delivered by tea farmers to the Tea Organization of Iran in 2017 (Iran Tea Organization, 2017) the acreage was 186.5 ha and the number of farmers was around 42,000. About 90 percent of tea farms are located in Guilan province and the rest in Mazandaran. Dry tea production has also increased from 70,000 t in 1993 to about 105,000 $\mathrm{t}$ in 2017 (Iran Tea Organization, 2017).

Despite its importance, Iranian tea farming is faced with a number of constraints which affect production efficiency and farmers livelihood. This industry is preforming blow its potential level. Yields and productivity are low due to rising production costs and improper agricultural practice. Addressing these issues requires adoption of policies and practices that may make headway to achieve reasonable production efficiency in this industry.

The notion of efficiency in agricultural sector is an interesting subject for empirical investigation. Productivity of agricultural production may be increased by efficient use of inputs. Agricultural production is the process of transforming inputs, such as capital, labor, seed, water, chemical fertilizer..., into goods and services. In this process, the ultimate objective of farm manager is output maximization, cost minimization, hence profit maximization. In this process, the manager should be concerned with efficiency in the use of inputs in order to achieve the objective.

There are two methods used in the literature for estimating production efficiency. First, stochastic frontier analysis (SFA), is an econometric approach that was simultaneously introduced by Aigner, Love and Schmidt (1977) as well as Meeusen and van den Broeck (1977). This method considers the subordinate relation between inputs and output and uses statistical techniques to estimate function parameters. The second method called data envelopment analysis (DEA) is a non-parametric approach or mathematical programming. This method is able to consider multiple inputs and output simultaneously, and inputs-output can be quantified using different units of measurements.

In recent years, there have been some studies conducted in Iran, considering production efficiency of agricultural crops, all using DEA methodology (Kazemi and Nikkhah, 2009; Mehrabi and Pakravan, 2009; Abedi et al., 2011; Amini et al., 2012; ZarraNezhad et al., 2012; Kavand et al., 2014). 
In recent years, there have been some studies in estimating production efficiency of tea farms in major producing countries, all using Stochastic Frontier Analysis (Basnayake and Guarantee, 2002; Saigenji and Zeller, 2009; Baten et al., 2010; Hong and Yabi, 2015a; Hong and Yabi, 2015b).

Basnayake and Gunaratne (2002) analyzed production efficiency of tea farms in Sri Lanka. They found that, average technical efficiency was around 64 percent. This score indicates "there is scope of further increasing the output by 36 percent without increasing the level of inputs. The authors also considering socio-economic factors affecting this inefficiency concluded that older farmers appeared to be more efficient than younger farmers.

Saugenji and Zeller (2009) studied the impact of contract farming on production efficiency and household income of the tea small holders in North Western Vietnam. The results showed that, production was significantly higher under contract farming. It was also found that membership in communist party, played a significant role in participation of tea farmers in contract program.

Baten (2010), indicate that the average technical efficiency of Bangladesh tea farmers was around 59 percent. This implies that there is a high potential of 41 percent for better use of inputs and reduction of costs in tea industry of Bangladesh.

Hong and Yabi (2015a), conducted a research on enhancement of efficiency perspective of tea production in Vietnam. The results showed that, the appropriate use of technology (sound input application) may increase average production of tea leaves by 10.4 percent. The technical efficiency of the inputs, surveyed from the farms, on average varied in the range of 62.1 to 97 percent.

In another effect, Hong and Yabi (2015b) assessed the use of inputs in tea production identifying the influential factors in Vietnam tea industry. Based on the estimated average elasticity of production (0.323), it was noticed that the production factors were utilized inefficiently in all surveyed farms. With regard to socio-economic factors, they found that, experience had positive effect on technical efficiency in input outputoriented model. Farmers with much experience in tea farming can produce more output with given inputs as compared to those with less experience.

Van Ho et al. (2018) applied propensity score matching to control self-selection, in assessing profit efficiency of safe and conventional tea farming. The results of this study indicate that, the average profit efficiency of tea farmers was around 74 percent, suggesting 26 percent of profit was lost due to inefficient use of inputs.

Although tea is a promising crop not only for farmer's income but also for economy as whole. Until now there has been no obvious research concerned with efficiency of tea production, In Iran. The present study hopefully would fill this gap. The objective of this research is to assess different types of production efficiency in traditional tea farms of Iran using data envelopment analysis approach and correlation analysis. Based on technical details, the study will provide useful information on the method in which farm should utilize resources efficiently to produce tea in the surveyed region. 


\section{Materials and methods}

Technical (TE) is be defined as the ability of a firm to maximize output from a given set of inputs. Allocative efficiency is the ability of a firm to use inputs in optimal proportions, resulting into maximum profit at minimum cost (Farell, 1957; Coelli et al., 2005).

The DEA is an analytical technique used for performance evaluation. It is a multifactor productivity exploration model used for assessing relative efficiencies of a homogenous set of decision making units (DMUS). The present study uses two main DEA models: CCR (Charnes-Cooper-Rhodes) and BCC (Baker-Charnes-Cooper). The CCR model is based on the assumption of constant return to scale (CRS) of the economic activities. The BCC model is based on the assumption of variable return to scale (VRS) of these activities. Assuming there are N DMUS, each of which uses K inputs and M outputs, then the relative efficiency score, is obtained by solving the following model.

CRS as (linear) mathematical programming, (nonparametric) model, was proposed by Charnes et al. (1918), which uses a "ratio-form" that defines "relative efficiency" as "ratio output to inputs" (Cooper et al., 2004).

$$
\begin{aligned}
& \operatorname{Max}_{\mu, v}\left(\mu^{\prime} y_{i}\right) \\
& \mathbb{s}: \\
& v^{\prime} x_{i}=1, \\
& \mu^{\prime} y_{j}-v^{\prime} x_{j} \leq 0, \quad j=1,2, \ldots, N \\
& \mu, v \geq 0,
\end{aligned}
$$

Assuming that we have data on $\mathrm{K}$ inputs and $\mathrm{M}$ outputs for $\mathrm{N}$ farm units or DMUs; then, the values of inputs and outputs for the ith DMU is represented by vectors $\mathrm{Xi}$ and Yi. The matrix of $\mathrm{K} \times \mathrm{N}$ inputs, which is denoted as $\mathrm{X}$, and the matrix of $\mathrm{M} \times \mathrm{N}$ outputs, which is denoted as $\mathrm{Y}$, represents the data for all N DMUs. The objective of DEA is to build a nonparametric envelopment frontier function on a set of data, so that, all observations are placed on or below the production function frontier. The most optimal version of DEA is its fractional form. In this model, there is a tendency to obtain a ratio of all outputs to all inputs for all individual DMUs; e.g., $u^{\prime} y_{j} / v^{\prime} x_{j}$, in which $\mathrm{u}$ is a vector of $\mathrm{M} \times 1$ of output weight and $\mathrm{v}$ is a vector of $\mathrm{K} \times 1$ of input weight. Equation (1) represents a fractional programming model (also called quotient function). This model can be converted into linear programming model Eq. 3, for selection of optimal weights (Coelli et al., 2002).

The values of $u$ and $v$, in objective function, i.e. Eq. (1), are determined under the condition that, the efficiency of the DUM is maximized with respect to the constraint assuming all measured efficiency scores should be smaller than or equal to 1 . The fractional version of this objective function (Eq. 1) has shortcoming, that is, it has indefinite answers. To avoid this problem, the constraint vxi $=1$ is added to the model. 


$$
\begin{aligned}
& \operatorname{Max}_{\mu, v}\left(\mu^{\prime} y_{i}\right) \\
& \boldsymbol{s}: \\
& v^{\prime} x_{i}=1, \\
& \mu^{\prime} y_{j}-v^{\prime} x_{j} \leq 0, \quad j=1,2, \ldots, N \\
& \mu, v \geq 0,
\end{aligned}
$$

Where the use of $\mu$ and $v$ instead of $v, u$ shows the variations. This equation is known as the incremental version of linear programming model.

The assumption of CRS is appropriate when all DMUs perform at optimal level (the flat portion of the long-run average cost curve). Imperfect competition generates financial limitations as well as some other problems that may result in a non-optimal performance of the DMU. Banker et al. (2005) proposed an extension of DEA with CRS assumption to calculate efficiency under variable return to scale.

Applying CRS when all DMUs do not function at optimal level will lead to incorrect measurement of TE, due to the impacts of scale efficiency (SE). On the other hand, applying VRS, allow us to measure TE which is free of SE impacts. To calculate efficiency under VRS assumption, one can include the constraint NI $\lambda=1$ (convexity) in Eq. (2) in order to adjust for linear programming role under constant return to scale (Coelli et al., 2002).

$$
\begin{aligned}
& \operatorname{Min}_{\theta, \lambda} \theta, \\
& \boldsymbol{s}: \\
& -y_{i}+Y \lambda \geq 0, \\
& \theta x_{i}-X \lambda \geq 0, \\
& N 1^{\prime} \lambda=1 \\
& \lambda \geq 0,
\end{aligned}
$$

Where, $\mathrm{N}$ is $\mathrm{N} \times 1$ vector of 1 . This approach develops a cross convex shell that can strongly cover all data points in constant unit, setting the conical shell of CRS. As a result, TE scores obtained by this approach are larger than or equal to the scores obtained under constant return to scale.

If data on price is available and the objective is cost minimization or income maximization, it will be possible to measure both technical and allocative efficiencies. To calculate TE, cost minimization is ideally used by assuming variable return to scale in input-oriented DEA model, as shown in Eq. (2). Hence, in cost minimization model, Eq. (3) is used for determining allocation efficiency. 


$$
\begin{aligned}
& \operatorname{Min}_{\lambda, x_{i}^{*}} w_{i}^{\prime} x_{i}^{*}, \\
& \boldsymbol{s}: \\
& -y_{i}+Y \lambda \geq 0, \\
& x_{i}^{*}-X \lambda \geq 0, \\
& N 1^{\prime} \lambda=1 \\
& \lambda \geq 0,
\end{aligned}
$$

Where, wi is a vector of the input prices related to the ith DMU.

A number of advantages are linked with the use of DEA. Its strengths are that, multiple inputs and output can be considered simultaneously; inputs and outputs can be quantified using different units of measurements; and not demanding a hypothesis of any functional form for inputs and outputs.

The data and information required for this survey research were collected and questionnaire is completed by personal interview in Fouman county of Guilan province, Iran, for the production year 2017 . The province is located within $36^{\circ} 27^{\prime}$ north latitude and $48^{\circ} 53^{\prime}$ and $50^{\circ} 34^{\prime}$ 'east longitude. The land ranges from mountains with elevations more than 3000 meters to coastal areas below sea level.

Figure 1. Location of the survey region in the north central of Iran

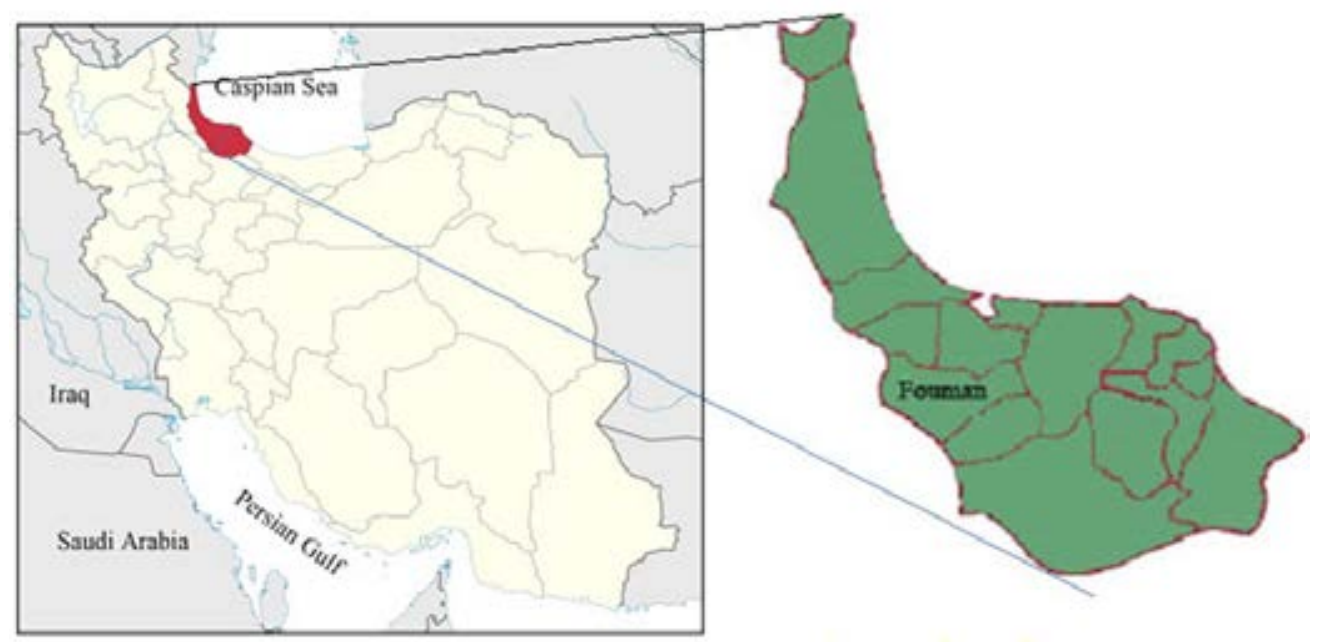

Guilan is the first largest tea-planting and tea-producing province in Iran, with 1,862 hectare of tea farm, producing 420,000 tons in green leaf $(105,000$ tons black tea) per year (the study year). The suitable natural conditions and temperate climate make Guilan tea have natural quality throughout Iran. The location of surveyed region is displayed in Fig. 1. The required information related to various inputs use are: the average farm land measured in hectare; the average total working hours of labor (man- 
day); the average amount of nitrogen fertilizer in kilogram per hectare and the average amount of phosphate fertilizer in kilogram per hectare. For the ease of computation, reduce errors and save time, a simple random sampling method was used to determine sample size and the tea plantations were chosen randomly from the surveyed region. This method is expressed as below.

$$
n=\frac{N(s \times t)^{2}}{(N-1) d^{2}+(s \times t)^{2}}
$$

Where, $n$, is the required sample size; $s$, is the standard deviation; $t$, the t-student statistic at the $\mathrm{p}<0.05$ level; $\mathrm{N}$, is the population size; and $\mathrm{d}$ is the error terms.

\section{Results and Discussions}

Data Envelopment Analysis was used to determine the production efficiency of 200 tea's farming units, which are the DMUs for this research, using the input - oriented approach with constant as well as variable return to scale. The results are presented in table 1 through 5 .

Table 1. Output and inputs used level (per ha)

\begin{tabular}{|l|l|l|l|l|}
\hline Inputs & Average & S.D. & MIN & MAX \\
\hline Land (ha) & 0.74 & 0.83 & 0.1 & 8 \\
\hline Labor (man-day) & 42.88 & 48.11 & 12 & 270 \\
\hline Nitrogen fertilizer $(\mathrm{kg})$ & 448.66 & 498.77 & 60 & 4800 \\
\hline Phosphate fertilizer $(\mathrm{kg})$ & 104.5 & 83.15 & 50 & 500 \\
\hline Grade 1 green leaf $(\mathrm{kg})$ & 2314.75 & 3047.14 & 100 & 32000 \\
\hline Grade 2 green leaf $(\mathrm{kg})$ & 3329.5 & 3047.14 & 300 & 35000 \\
\hline
\end{tabular}

The farm size is the total land area devoted to tea production by farming unit, during the period of study, expressed in hectares. It has been observed that, the average tea farm size is around 0.74 ha, ranging from 0.1 to 8 ha, revealing vast variation in farm size, among tea farm holders. This result reveals the tea farmers in the surveyed region mostly engaged in smaller sized farms, often achieving greater income per hectare and are more technically efficient than the larger sized farms. One could argue that, this might result from the direct supervisory and daily oversight roles of the owner. Thus, on the other hand, however, the owner of a large farm often has more capital and could take advantage of the economy of scale to achieve higher return and efficiency. Therefore, the influence of farm size on efficiency is predicted to be either positive or negative.

The average human labor per hector, including hired and family labors was 42.88 men days. The score ranges from 12 men-days to 270 men-days, indicating that tea farming activities are highly labor intensive. 
Fertilizer is considered as important inputs to increase tea yield. Its use is expected to have a positive effect on efficiency, if the recommended quantities are applied under the demanding soil condition (Njeru, 2010). When the use is contrary to the recommended practice or does not consider the soil fertility condition, it could lead to inefficiency in tea production. In this study, the average fertilizer level was $445.66 \mathrm{~kg} / \mathrm{ha}$. There was a high variation in the amount of fertilizer application per hectare, with the range from 60 to 4,800 kilograms. This finding may substantiate the quotation cited by Njeru, which, states that, the use of chemical fertilizer could have positive or negative impact on the efficiency of this input on the cultivated soil. The result is consistent with finding by Hong Nguyen B. and Yabe M. (2015)

As depicted in Table 2, the of average technical, allocative and economic efficiencies scores were 86, 71 and 61 percent respectively, assuming constant return to scale. This Table also reports the lowest scores for these three concepts were around 64, 24 and 20 percent respectively. The economic implication of the technical efficiency score (86) implies that, there is still scope of further increasing the output by 14 percent without increasing the amount of inputs.

Table 2. Statistical results of technical, allocative and economic efficiency assuming constant return to scale

\begin{tabular}{|l|l|l|l|l|}
\hline Efficiency type & Average & Standard Deviation & Minimum & Maximum \\
\hline Technical & 0.86 & 0.08 & 0.64 & 1 \\
\hline Allocative & 0.71 & 0.21 & 0.24 & 1 \\
\hline Economic & 0.61 & 0.19 & 0.20 & 1 \\
\hline
\end{tabular}

Table 3 presents, the average of technical, allocative and economic efficiency scores, respectively, assuming variable return to scale. The calculated scores for technical efficiency reveal that, the surveyed farmers can reduce the amount of inputs by 13 percent without losing the current levels of output.

Table 3. Statistical results of technical, allocative and economic efficiency assuming variable return to scale

\begin{tabular}{|l|l|l|l|l|}
\hline Efficiency type & Average & Standard Deviation & Minimum & Maximum \\
\hline Technical & 0.87 & 0.08 & 0.65 & 1 \\
\hline Allocative & 0.74 & 0.18 & 0.30 & 1 \\
\hline Economic & 0.65 & 0.17 & 0.28 & 1 \\
\hline
\end{tabular}

The frequency percent distribution of technical, allocative and economic efficiency assuming constant return to scale and increasing return to scale are presented in Table 4 and Table 5. In Table 4, the highest frequency score of technical efficiency was 58 for 0.85-1 interval. The score for allocative efficiency was 36 for interval $0.85-1$, and for economic efficiency 34 , for interval 0.37-0.53. 
Table 4. Frequency (\%) distributions of technical, allocative and economic efficiency assuming constant return to scale

\begin{tabular}{|l|l|l|l|l|}
\hline Efficiency type & $0.37-0.53$ & $0.53-0.69$ & $0.69-0.85$ & $0.85-1$ \\
\hline Technical & 0 & 3.5 & 38.5 & 58 \\
\hline Allocative & 30 & 9.5 & 24.5 & 36 \\
\hline Economic & 34 & 18 & 37 & 11 \\
\hline
\end{tabular}

Assuming variable return to scale, the highest frequency distributions of technical, allocative and economic efficiency were 52, 33.5 and 30 for intervals $0.85-1,0.85-1$, and $0.37-0.53$ respectively (Table 5 ). The results for scale efficiency show that, the average scale efficiency for surveyed farms was 97 percent and the lowest scare was 77 percent. It was also found that 41.5 percent of surveyed farms had an increasing return to scale; 44.5 percent had diminishing return to scale, and 14 percent had constant return to scale.

Table 5. Frequency (\%) distributions of technical allocative and economic efficiency assuming variable return to scale

\begin{tabular}{lllll}
\hline Efficiency type & $0.37-0.53$ & $0.53-0.69$ & $0.69-0.85$ & $0.85-1$ \\
\hline Technical & 0 & 8.5 & 39.5 & 52 \\
Allocative & 29 & 9.5 & 28 & 33.5 \\
Economic & 30 & 28.5 & 24.5 & 17 \\
\hline
\end{tabular}

For policy implications, it is useful to determine which socio-economic characteristics of farmer's have impact on production efficiencies of tea farms in the surveyed region. The socio economic factors chosen for this study were: tea farmer's age (AGE), educational level (EDU) on an ordinal scale of reading and writing literacy (Level 1), elementary school (Level 2), intermediate school (Level 3), diploma (Level 4), associate degree (Level 5 ) and bachelor degree (Level 6), family size (FS), and neighbors and acquaintances participation in tea farming practice (COP) on an ordinal scale of very low (Leve 11), low ( Leve 12), moderate (Level 3), high (Level 4), and very high (Level 5). The descriptive statistics of these variables are given in Table 6.

Table 6. Descriptive statistics of the variables influencing technical efficiency score

\begin{tabular}{|l|l|l|l|l|}
\hline Variable & Average & Standard deviation & Minimum & Maximum \\
\hline AGE & 53.48 & 10.96 & 27 & 80 \\
\hline EDU & 1.77 & 1.77 & 1 & 6 \\
\hline FS & 4.16 & 1.47 & 2 & 8 \\
\hline COP & 3.68 & 0.68 & 1 & 5 \\
\hline
\end{tabular}

Age of the tea farmer is defined in years. In this research the impact of age on farming efficiency is positive; as such, older farmers appeared to be more efficient than younger farmers. This may be due to their proper managerial skills, which they have learnt over 
time. This study found the correlation between tea farmer's age and technical efficiency is significant and positive at $\mathrm{P}<0.01 \mathrm{Level}$. This result is consistent with the finding of Basnayake et al. (2002).

The positive effect of education on the production efficiency of farming units had been established by Coelli and Battese (1996). Basnayake et al. (2002) and Hong and Yabe (2015) also confirmed the positive effect of proper schooling on efficient use of resourse of tea farms. This study also found the correlation between tea farmer's educational level and technical efficiency significant and positive at $\mathrm{P}<0.01$ level.

The family size refers to the number of individuals that are the resident in the owner of tea farm's house. In this study we found that, the impact of family size on technical efficiency is positive. This indicates that, farmers with large family size are able to support their labor requirement for farming operation, more readily and perform these operations at appropriate time.

Table 7. Correlation between technical efficiency score and descriptive variables

\begin{tabular}{|l|l|l|}
\hline Variable & Coefficient of correlation & Probability level \\
\hline AGE & 0.147 & 0.019 \\
\hline EDU & 0.267 & 0.00 \\
\hline FN & 0.141 & 0.024 \\
\hline COP & -0.125 & 0.039 \\
\hline
\end{tabular}

Neighbors and acquaintances participation in tea farming practice had negative and significant effect on technical efficiency. This result indicates that, when farmers do not have reliable labor at appropriate time, they are confronted with low production efficiency.

Table 8. Input savings to achieve technical efficiency

\begin{tabular}{|l|l|l|}
\hline Variable & CRS & VRS \\
\hline Land & -18.47 & -17.77 \\
\hline Labor & -12.53 & -10.93 \\
\hline Nitrogen fertilizer & -48.83 & -46.53 \\
\hline Phosphate fertilizer & -30.23 & -27.99 \\
\hline
\end{tabular}

The results in Table 8 indicate that in the case of constant return to scale showed that on average, inefficient units with a 12.52 percent reduction in labor use can reach the efficiency frontier. This number, for the case of variable return to scale is 10.93 . The results in table 3 also indicate that in the case of constant return to scale on average inefficient units with a 48.83 percent reduction in nitrogen may reach the efficiency frontier. This number for the case of variable return to scale is 43.53 . 


\section{Conclusions}

There is a considerable argument with the notion that, an effective economic development plan, depends on promoting productivity and output growth in agricultural sector. Tea as a promising crop boosts farmer's earning and the national economy of producing countries.

Tea production in Iran is generally characterized by small- sized farms. As such is the case for the surveyed region Fouman, located in Guilan province north of Iran with an average being 0.74 ha in size. This industry has a key role in generating extra earning and seasonal jobs in the study region.

The present study used Data Envelopment Analysis (DEA) to determine efficiency of tea production in the Fouman County of Guilan Province, Iran, using filed survey data obtained from 200 tea farms spread over this County during 2016-2017. The study also characterized tea farmers into social and economic classes and evaluates their impact on resource use efficiency.

Results of this research clearly indicate that, the average technical efficiency score of tea production in this region is around 86 percent, with wide variation among farmers ranging from 64 percent to 100 . This suggests that, there are considerable opportunities for tea farmers to increase their productive allocative and economic efficiencies.

In order to achieve efficiency in inefficient tea farming units, the results indicate that, the farmers should save nitrogen fertilizer more than 40 percent and phosphate fertilizer more than 30 percent (table 8). Since the most of these chemicals are obtained from overseas, and given the fact that foreign exchange rate is rapidly increasing, this reveals that, the efficiency of tea production is vulnerable to changes in price of chemical fertilizers. In order to overcome this problem, we suggest that the government should take course of actions on following issues: intensifying quantity control of chemical fertilizers circulated in the markets; regulating and balancing the supply and demand of fertilizers; regulating the chemical fertilizer imports through tariff policies as well as, support policies to improve the capacity of the distribution system to ensure that fertilizers are circulated from production and import sites to the tea farms.

The results of this study clearly revealed that, in order to achieve efficiency in inefficient tea farm units, the farmers should save nitrogen fertilizer more than 40 percent as well as phosphate fertilizer more than 30 percent. Since the most amounts of chemical fertilizers are supplied from overseas and given the fact that foreign exchange rate is increasing; this means that, the efficiency of tea production is vulnerable to changes in prices of chemical fertilizer. In order to overcome this problem, we suggest that the government should take course of actions on following issues:

Intensifying quantity control of chemical fertilizer circulated in the markets; regulating and balancing the supply and demand of fertilizers; regulating the chemical fertilizer imparts through tariff policies as well as support policies to improve the capacity of the distribution system to ensure that fertilizers are circulated from production and import to the farms. The study found that a positive correlation between education level and 
TE. Therefore, years of education should have a positive impact on better managerial agricultural practices.

This research achieved important finding that change tea farmers opinion. Generally, the farmers often think that the best way to have more output is by using inputs as much as possible. In fact, the results indicate that, the farmers in surveyed region (Fouman) should make an effect on reducing inputs (as indicated in Table 8), which will save them production cost.

According to the results, the effect of family size on the efficiency of tea farming is positive. Therefore, if the farmer by virtue of its large size supply part of the labor requirement for the farming practice to reduce reliance on hired labor, it becomes possible to invest the unspent funds in other areas of the farm business to enhance efficiency.

According to the results, older (aged) farmers were more efficient than younger farmers. This may be due to their good managerial skills, which they have learnt over time. Hence the younger farmers should be encouraged to work with older farmers.

Educated farmers are found to be more efficient than the uneducated farmers. This may be because their knowledge, gained from education has provided them a background to take proper decisions. It would be easier for them to grasp the information provided them by the experts. Therefore, it is necessary to increase educate facilitates.

The mean technical efficiency of the tea farmers in the surveyed region is 87 percent, with wide variation among farmers, ranging from a minimum of 65 a maximum of 100 percent (Table 3). Such a considerable difference between the minimum and maximum technical efficiency, indicates that, it is possible to increase the current level of output by 13 percent, given fixed inputs; i.e., at the same level of technology, this gap may be reduced through improved technical efficiency. Thus to increase the tea production in the survey region, authorizes of the Iran Tea Organization are recommended to increase the level of farmers' knowledge through promotional services center.

The result of socio-economic characteristics such as: age, educational level, family size as well as neighbors and acquaintances participation in tea farming practice on technical efficiency, showed that: there exist a positive and statistically significant relationship between tea farmers' age and efficiency, i.e. as the age increases the efficiency increases. The relationship between tea farmers' level of education and their technical efficiency is positive, i.e. as higher the number of years of school the farmer has had in formal education, the higher the technical efficiency. Thus, the tea farmer's age and level of education is directly related to their technical efficiency. There exist a negative and statically significant correlation between the participation of neighbors and acquaintances in farming practice with technical efficiency; hence, according to this result it seems timely access to the labor requirement for necessary farming practice at proper time is very important in achieving technical efficiency. Therefore, this founding suggests the development of mechanization should be considered as a major strategy for planner of policy makers. 


\section{Conflict of interests}

The authors declare no conflict of interest.

\section{References}

1. Abedi, M., Mohamadi, H., \& Ghafari, M. (2016). Efficiency and profitability of trout farming industry in Fars Province, Iran, Journal of Agricultural Economics, 5(2): 93-123. (Persian)

2. Aigner, D., Lovell, C.A.K., \& Schmidt, P. (1977). Formulation and estimation of stochastic frontier production functions models. Journal of Econometrics. 6(1): 21-37.

3. Amini, S.H. Yazdani, S., Chizari, A.H. \& Borjujeni, P.A. (2012). Measuring the efficiency of industrial dairy cattle breeding farms, using data envelopment analysis: A case in Southern Tehran Province, Iran. Agricultural Economic Research, 4(1): 105-122. (Persian).

4. Ghasemi, A. (2008). Effect of Structural Reforms in the Tea Industry, Journal of Commercial Reviews, 7(4): 25-39.

5. Van Ho, B., Nanseki, T. \& Chomei, Y. (2018). Profit efficiency of tea farmers: case study of safe and conventional farmers in Northern Vietnam, Environmental development and sustainability. 4(4): 1-19.

6. Banker, R.D., Charnes, A., \& Cooper, W.W., (1984). Some models for estimating technical and scale inefficiencies in data envelopment analysis, Management Sciences, 30(3): 1078-1092.

7. Basnyake, B. M. J. K. \& Gunaratne. L. H. P.,(2002). Estimation of technical efficiency and it's determinants in the tea small holding sector in the mid country wet zone of Sri Lanka, Sri Lankan Journal of Agricultural Economics, 4(1): 137-150.

8. Baten, A., Kamil, A.A., \& Haque, M.A. (2010). Productive efficiency of tea industry: A stochastic frontier approach, African Journal of Biotechnology, 25(2): 3808-3816.

9. Charnes, A., Copper, W.W. \& Rhodes, E, (1978). Measuring the efficiency of decision making units, European Journal of Operation of Research, 2(3): 429-444.

10. Coelli, T.J., Rao, D.S.P, O’Donnell, C.J., \& Battese, G.E., (2005). An introduction to efficiency and productivity analysis, Springer Science and Business Press.

11. Coelli T.J. \& Battese, G.E. (1996). Identification of factors which influence the technical inefficiency of Indian farmers, Australian Journal of Agricultural Economics, 40(2): 103-108.

12. Cooper, W.W., Seiford, L.M. \& Zhu, J. (2004). Data envelopment analysis: models and interpretations.” In: Cooper, W.W., Seiford, L.M. and Zhu, J. (eds.) hand book on data envelopment, analysis, Kluwer Academic Publisher, Boston, 2004: 1-34.

13. Farrel, M.J, (1957). Measurement of productive efficiency. Journal of the Royal Statistical Society. 1(1): 233-240. 
14. Moezi, Gh. (2009). Tea through Time, Abzian Publishing Press. (In Persian)

15. Hong, N. B. \& Yabe, M., (2013). Resource use efficiency of tea production in Vietnam: Using Translog SFA model, Journal of Agricultural Sciences; 7(9): 160- 176.

16. Hong, N.B. \& Yabe, M. (2015). Profit efficiency of tea production in the Northern Mountainous Region of Vietnam, Journal of the International Society for Southeast Asian Agricultural Sciences, 21(1): 1-17.

17. Iran Statistical Center: Survey of Agriculture, (2016).

18. Iran Tea Organization Data Base, (2017).

19. Iran Tea Organization, (2017). Report of tea production.

20. Iran Tea Report, Iran Tea Company Publication, (1958).

21. Iran Tea Report, Iran Tea Company Publication, (1972).

22. Kavand, H. Kalbali, A. \& Sebohai, M. (2014). Application of data envelopment analysis, considering efficiency of saffron production, Journal of Saffron Technology and Cultivation, 2(1): 17-29. (In Persian)

23. Kazemi, M. \& Nikkha, R. (2009). Application of data envelopment analysis in measuring and analyzing relative efficiency of wheat cultivation: Case of Khorasan-e Razavi, Iran. Agricultural Economics and Development, 23(2): 87-94. (In Persian)

24. Mehrabi, H. \& Pakravan, M.R. (2009). Estimating efficiencies and return to scale of sunflower producers in Khoy Township, Iran. Agricultural Economic and Development, 23(2): 95-102. (In Persian).

25. Meeusem, W., \& van den Broeck, J. (1977). Efficiency estimation from CobbDouglas production functions with composed error. International Economic Review, 5(3): 435-444.

26. Nguyen, H. P., Wattanachai, P., Kasem, S., Nguyen. T. Q., Dang, V. T., Nguyen, X. C., \& Luong, T. N. V. (2015). Comparison among chemical, GAP and organic method for tea cultivation in Vietnam, Journal of Agricultural Technology, 11(8): 1713-1730.

27. Njeru, J. (2010). Factors influencing Technical Efficiencies among Selected Wheat Farmers in Uasian Gishu District, Kenya. AERC Research Paper 206, African Economic Research Consortium, Nairobi, Kenya.

28. Saigenji, Y. \& Zeller, M. (2000). Effect of contract farming on tea production in the Northern Mountainous region of Vietnam, Economic Conformance, Beijing, China.

29. World Food Organization, (2017). Database statistics.

30. Zarra-Nezhad, M., Bavarsad, B., \& Noroozi, M. N. (2012). Study of technical efficiency of rice farmers in Iran: a case of Kohghiluyeh and Boyer-Ahmad province, Quarterly Journal of Quantitative Economics, 8(4): 43-125. 